\title{
Greenhouse Gas Emissions from Membrane Bioreactors
}

\author{
G. Mannina ${ }^{1(\bowtie)}$, M. Capodici $^{1}$, A. Cosenza $^{1}$, D. Di Trapani ${ }^{1}$, \\ and Mark C.M. van Loosdrecht ${ }^{2}$ \\ 1 Dipartimento di Ingegneria Civile, Ambientale, Aerospaziale, dei Materiali, \\ Università di Palermo, Viale delle Scienze, Ed. 8, 90128 Palermo, Italy \\ 2 Department of Biotechnology, Delft University of Technology, Julianalaan 67, \\ 2628 BC Delft, Netherlands
}

\begin{abstract}
Nowadays, it is widely accepted that wastewater treatment plants (WWTPs) are significant sources of greenhouse gas (GHG) emission, contributing to the anthropogenic sources. Among the GHG emitted from WWTPs, nitrous oxide $\left(\mathrm{N}_{2} \mathrm{O}\right)$ has been identified of having the major interest/concern, since its high global warming potential (GWP), is 298 times higher than that of $\mathrm{CO}_{2}$ and also to its capability to react with stratospheric ozone causing the layer depletion. Up to now, most of the experimental investigations have been carried out on conventional activated sludge (CAS) processes. The knowledge of $\mathrm{N}_{2} \mathrm{O}$ emission from advanced technologies such membrane bioreactors (MBRs) is still very limited. The present paper is aimed at providing a picture of the GHG emissions from MBR systems. In particular, data of $\mathrm{N}_{2} \mathrm{O}$ acquired from pilot plant systems monitoring are here presented. The key aim of the study was to highlight the effect of wastewater features and operational conditions on $\mathrm{N}_{2} \mathrm{O}$ production/emission from MBRs.
\end{abstract}

Keywords: Wastewater treatment $\cdot$ Global warming $\cdot$ Filtration $\cdot$ Nutrients

\section{Introduction}

During the last decade, the awareness that wastewater treatment plants (WWTPs) are responsible of greenhouse gas emissions has considerably increased. The hard work done by the Intergovernmental Panel on Climate Change, aimed at identifying the causes, impacts and possible response strategies for mitigating climate change, has allowed to recognize the sector of waste and wastewater as accounting for about $3 \%$ of global GHG emissions (Climate Change 2007; IPCC 2013). The US Environmental Protection Agency (2013) estimated that the wastewater treatment sector was responsible for over $5 \%$ of global non- carbon dioxide GHG emissions in 2005, and predicted that GHG emission would increase by $27 \%$ by 2030 .

It is widely accepted in literature that WWTPs emit GHGs through three main sources, i.e., direct, indirect internal and indirect external (GWRC 2011). Direct GHG emissions are due to the biological processes occurring inside the WWTP and represent the catabolite or obligate intermediate of reaction. Indirect GHG internal emissions are mainly due to the consumption of electrical or thermal energy. Finally, indirect GHG 
external emissions are mainly related to sources not directly controlled within the WWTP.

The acquired awareness of "WWTP as source of GHG" has contributed to broaden the traditional goal of WWTPs to the GHG matter. Indeed, the traditional aim of WWTPs to achieve very stringent effluent limit includes now the GHG emission issue (Flores-Alsina et al. 2011a).

Among the GHG emitted from WWTPs, $\mathrm{N}_{2} \mathrm{O}$ has been identified of having the major interest. Despite the amount of $\mathrm{N}_{2} \mathrm{O}$ emitted from WWTPs is considerably lower than $\mathrm{CO}_{2}$ or $\mathrm{CH}_{4}$, the major interest on its emission from WWTPs is due to its high global warming potential (GWP), 298 times higher than that of $\mathrm{CO}_{2}$, and to its capability to react with stratospheric ozone causing the layer depletion (IPCC 2007).

$\mathrm{N}_{2} \mathrm{O}$ is mainly produced in the biological nitrogen removal (BNR) processes via nitrification and denitrification both from autotrophic and heterotrophic bacteria (Kampschreur et al. 2009). The main part of the study on $\mathrm{N}_{2} \mathrm{O}$ are related to conventional activated sludge systems (CAS) and the knowledge acquired may not be transferred into innovative systems such as membrane bioreactors (MBR). Indeed, MBRs are characterized by some specific peculiarities (biomass selection; absence of secondary clarifier which can contribute in $\mathrm{N}_{2} \mathrm{O}$ production; intensive aeration for fouling mitigation in membrane compartment which can promote $\mathrm{N} 2 \mathrm{O}$ stripping; etc.), which may hamper a direct transferability of the results derived for CAS systems.

The main goal of this paper is to summarize the key elements influencing the $\mathrm{N}_{2} \mathrm{O}$ production/emission from MBR WWTPs.

\section{Materials and Methods}

During the Italian research project PRIN2012 entitled "Energy consumption and GreenHouse Gas (GHG) emissions in the wastewater treatment plants: a decision support system for planning and management" 2 years of experimental activities were carried out. The main aim was to assess the effect of different MBR configurations, influent wastewater (municipal or industrial), operational conditions (sludge retention time, SRT, carbon-to-nitrogen ratio, $\mathrm{C} / \mathrm{N}$, hydraulic retention time, HRT) and membrane modules on the $\mathrm{N}_{2} \mathrm{O}$ production/emission. In Fig. 1 the experimental lay out investigated are depicted.

Briefly, pilot plant N.1 (SB-MBR) was designed according to a pre-denitrification scheme in a sequential feeding mode. It consisted of two in-series reactors anoxic-aerobic followed by a MBR compartment (Zenon, ZW 10). The experimental campaign was divided into six Phases during which the salt concentration was gradually increased from 0 to $10 \mathrm{~g} \mathrm{NaCl} \mathrm{L}^{-1}$. Pilot plant N.2 (DN-MBR) consisted of two in-series reactors anoxic-aerobic fed in continuous followed by a MBR compartment. The experimental campaign was divided in two Phases: increasing salinity of the influent (from $10 \mathrm{~g} \mathrm{NaCl} \mathrm{L}^{-1}$ up to $20 \mathrm{~g} \mathrm{NaCl} \mathrm{L}^{-1}$ ) during Phase I, while in Phase II the inlet wastewater was characterized by constant salinity $\left(20 \mathrm{~g} \mathrm{NaCl} \mathrm{L}^{-1}\right)$ and hydrocarbons dosage. Anaerobic, anoxic and aerobic in-series reactors, according to the University of Cape Town (UCT) scheme (Ekama et al. 1983), characterized pilot plant N.3 (UCT-MBR). The MBR module was UF module Koch PURON® 3 bundle. 

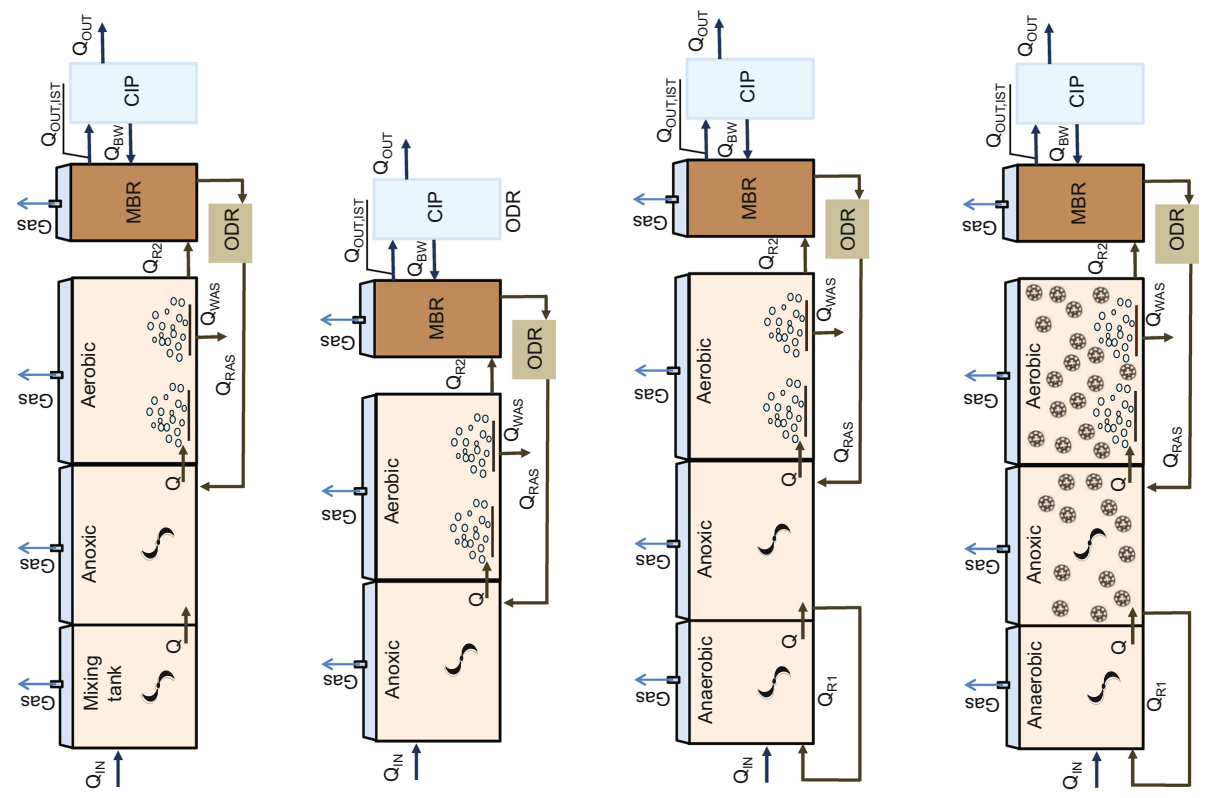

Fig. 1. Schematic layout of the investigated pilot plants: SB-MBR (a), pre-denitrification MBR (b), UCT-MBR (c) and UCT-MB-MBR (d)

The experimental campaign was divided in two Phases, each characterized by a different value of the inlet $\mathrm{C} / \mathrm{N}$ ratio: $\mathrm{C} / \mathrm{N}=10$ and $\mathrm{C} / \mathrm{N}=5$ during Phase I and Phase II respectively. Pilot plant N.4, (UCT-MB-MBR), consisted of the same scheme of Pilot Plant N.3. Furthermore, suspended plastic carriers (Amitech) for biofilm growth have been added to the anoxic and the aerobic reactors, with filling fraction of 15 and 40. The experimental campaign was aimed at investigating the influence of operational variables (namely, SRT, C/N ratio and HRT-SRT) on $\mathrm{N}_{2} \mathrm{O}$ production and emission.

For further details on pilot plant description as well as on experimental campaings the reader is addressed to literature (Mannina et al. 2016a, b, c; 2017a, b).

Samples from the liquid bulk of each reactor were collected and the dissolved nitrous oxide was extracted in accordance with procedure proposed by (Kimochi et al. 1998). Sample of the permeate flow were also collected in order to quantify the dissolved $\mathrm{N}_{2} \mathrm{O}$ concentration discharged with the effluent flow rate. Both, dissolved and head-space, samples were analyzed by means of Gas Chromatography using an Electron Capture Detector (ECD) in order to assess the $\mathrm{N}_{2} \mathrm{O}$ concentration. Furthermore, a hot wire anemometer allowed the air velocity measurement within the funnel of each reactor and thus the flux of nitrous oxide emitted from the liquid surface of each reactor was assessed. The nitrous oxide emission was assessed also in terms of Emission Factor (EF) evaluated in accordance with method proposed by (Tsuneda et al. 2005). Moreover, the abundance of measured $\mathrm{N}_{2} \mathrm{O}$ concentrations, dissolved and emitted, coupled with the detailed knowledge of the liquid fluxes passing through each reactor allowed the calculation of nitrous oxide mass balance that highlighted the production or the consumption of $\mathrm{N}_{2} \mathrm{O}$ within each reactor. 


\section{Results}

Data collected over almost two years underline the huge variability of $\mathrm{N}_{2} \mathrm{O}$ concentration measured; indeed, the nitrous oxide concentrations ranged within 7 orders of magnitude (from $10^{-1} \mu \mathrm{g} \mathrm{N} \mathrm{N}_{2} \mathrm{O}-\mathrm{N} \mathrm{L}^{-1}$ up to $10^{5} \mu \mathrm{g} \mathrm{N}_{2} \mathrm{O}-\mathrm{N} \mathrm{L}^{-1}$ ).

Such extreme variability in $\mathrm{N}_{2} \mathrm{O}$ concentrations resulted also in a wide range of emission factor measured during the experimentation. In Fig. 3 the average value of emission factors measured for each experimental ley out are depicted.

Data depicted in Fig. 2 highlight the influence exerted by the layout on the nitrous oxide emission. In details, the DN-MBR scheme result as featured by the highest emission factor (16\% of influent nitrogen on average). It is worth noticing that also the influent wastewater composition played a significant role in increasing the $\mathrm{N}_{2} \mathrm{O}$ emission. Indeed the DN-SBR scheme treated an influent wastewater composed also by salt and diesel fuel. With regard to the UCT-MBR and UCT-MB-MBR configuration, the scarcity of carbon availability imposed during the lowest values of $\mathrm{C} / \mathrm{N}$ ratio resulted in an increase of $\mathrm{N}_{2} \mathrm{O}$ emission likely due to a limitation of denitrification process. To summarize, the configuration that yielded the lowest EF was the UCT-MB-MBR that was featured by a mean emission equal to $0.5 \%$ of influent nitrogen. Actually, the operational condition influenced the emission also during this period. As an example, when an SRT $=30 \mathrm{~d}$ was imposed to the pilot plant, the mean emission factor resulted equal to $7.57 \%$.

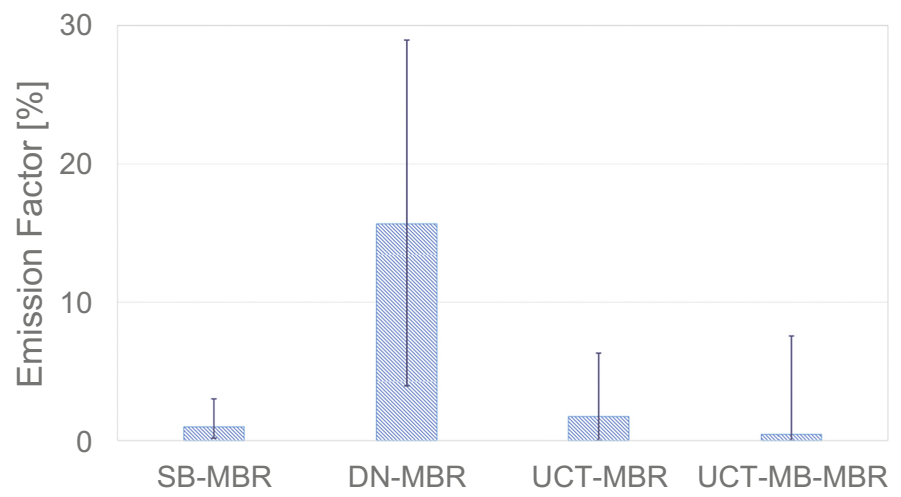

Fig. 2. Nitrous oxide concentration measured in the Head space and in the liquid bulk of Aerobic (a) and Anoxic (b) reactors over the experimentation

In order to describe also the role played by each reactor in contributing to the total emission, in Fig. 3 is depicted a comparison of mean EF assessed for each reactor during UCT-MBR and UCT-MB-MBR configuration.

Data depicted in Fig. 3 highlight the strong reduction in EF during the UCT-MB-MBR layout. Such result is likely due to an improvement in biological performances exerted by the co presence of both suspended and attached biomass. The 


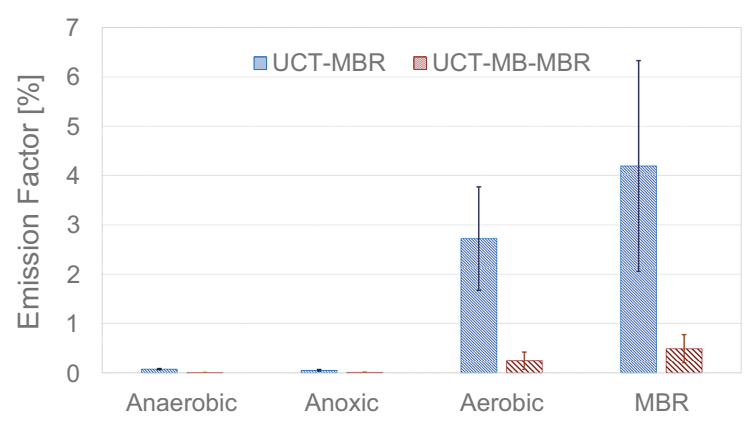

Fig. 3. Comparison of mean EF measured in each biological reactor during the UCT-MBR and UCT-MB-MBR layout

biofilm presence improved the nitrogen removal efficiency thus leading to a lower $\mathrm{N}_{2} \mathrm{O}$ emission.

In order to compare direct and indirect emission, in Fig. 4 data related to the relationship between the air flow versus, indirect (Fig. 4a) and direct emissions (Fig. 4b) obtained are reported.
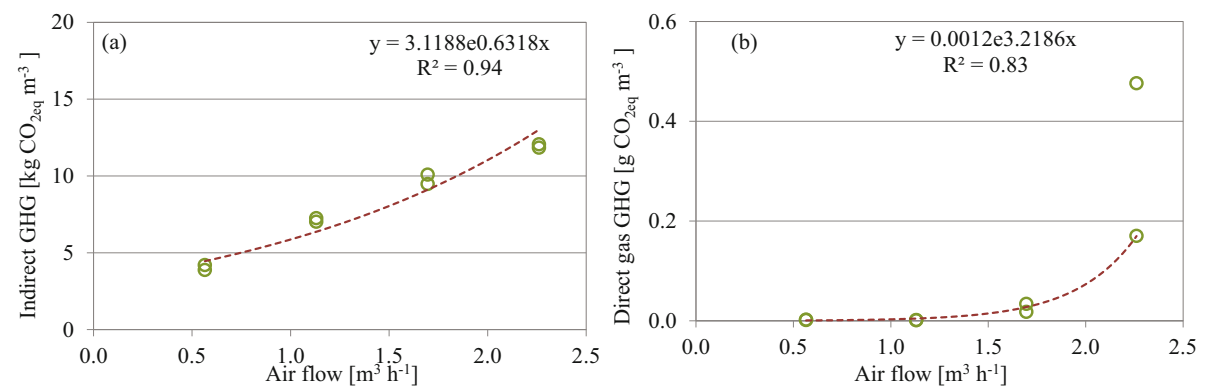

Fig. 4. Relationship between the air flow and indirect GHG emissions (a); correlation between the air flow rate direct GHG emissions (b)

An exponential relationship $\left(\mathrm{R}^{2}=0.83\right)$ between the air flow and the indirect (Fig. 4a) and direct (Fig. 4b) GHG emissions was found.

In terms of GHG emissions (both direct and indirect) the lowest air flow $\left(0.6 \mathrm{~m}^{3} \mathrm{~h}^{-1}\right)$ seems to be more adequate than the others. Such result highlights the interlinkages between different involved phenomena. Indeed, a "multiple trade-off" has to be performed for identifying the best value of the air flow to mitigate GHG emissions and to reduce the EQI and OCs value. 


\section{Conclusions}

The understanding of processes that enhance GHG emission as well as the knowledge of operational varibles and conditions that favour their production represent key challenges investigated by the scientific community in the last years. Indeed, many efforts have been recently evoted in experimental activities with the aim to: i. assessing the main mechanisms of GHG formation, ii. evaluating the operational conditions that favour their production.

In this context, some aspects related to GHG production/emission are still poorly understood and deserve further investigations. For instance, despite many studies revealed that $\mathrm{N}_{2} \mathrm{O}$ formation mostly derives from $\mathrm{AOB}$ activity, the conditions that trigger its formation are still not clear. Moreover, from a management point of view, literature studies highlighted the need to focus on GHG emission from WWTPs. Indeed, if the target is only represented by the liquid effluent quality coupled to the minimization of the operational cost, the GHG emission might be significant. As an example, the decrease of the dissolved oxygen set-point inside the nitrification reactor could promote the increase of $\mathrm{N}_{2} \mathrm{O}$ production due to incomplete nitrification, despite the reduction of the operational costs.

In this light, a plant wide mathematical modelling could represent a useful tool for the comparison of different scenarios (in terms of either design or management) for the evaluation of the best system performance, referring to both quality of the liquid effluent, reduction of gaseous emissions and operational costs reduction.

In this light, the aim of the scientific community should be the build-up of simplified mathematical tools, derived by complex dynamic mathematical models, to be used as decision support systems able to simulate the quality of gaseous and liquid emissions from WWTPs and to provide useful indications for the optimization of the system management.

Acknowledgements. This work forms part of a research project supported by grant of the Italian Ministry of Education, University and Research (MIUR) through the Research project of national interest PRIN2012 (D.M. 28 dicembre 2012 n. 957/Ric - Prot. 2012PTZAMC) entitled "Energy consumption and GreenHouse Gas (GHG) emissions in the wastewater treatment plants: a decision support system for planning and management - http://ghgfromwwtp.unipa.it" in which the first author of this paper is the Principal Investigator.

\section{References}

Ekama GA, Siebritz IP, Marais GR (1983) Considerations in the process design of nutrient removal activated sludge processes. Water Sci Technol 15:285-318

Flores-Alsina X, Arnell M, Amerlinck Y, Corominas L, Gernaey KV, Guo L, Lindblom E, Nopens I, Porro J, Shaw A, Vanrolleghem PA, Jeppsson U (2011a) A dynamic modelling approach to evaluate GHG emissions from wastewater treatment plants. In: Proceedings of World Congress on Water, Climate and Energy

GWRC-Global Water Research Coalition (2011) $\mathrm{N}_{2} \mathrm{O}$ and $\mathrm{CH}_{4}$ emission from wastewater collection and treatment systems - state of the science report, 2011-29, London, UK 
IPCC (2007) Changes in atmospheric constituents and in radiative forcing. In: Solomon S et al. (eds.) Climate change 2007: the physical science basis. Contribution of working group I to the fourth assessment report of the intergovernmental panel on climate change. Cambridge University Press, Cambridge, pp 114-143

IPCC, Climate Change (2013) The physical science basis. In: Contribution of working group I to the fifth assessment report of the intergovernmental panel on climate change. Cambridge University Press, Cambridge, New York, p 1535

Kampschreur MJ, Temmink H, Kleerebezem R, Jetten MSM, van Loosdrecht MCM (2009) Nitrous oxide emission during wastewater treatment. Water Res 43:4093-4103

Kimochi Y, Inamori Y, Mizuochi M, Xu K-Q, Matsumura M (1998) Nitrogen removal and $\mathrm{N}_{2} \mathrm{O}$ emission in a full-scale domestic wastewater treatment plant with intermittent aeration. J Ferment Bioeng 86(2):202-206

Mannina G, Morici C, Cosenza A, Di Trapani D, Ødegaard H (2016a) Greenhouse gases from sequential batch membrane bioreactors: a pilot plant case study. Biochem Eng J 112:114-122

Mannina G, Cosenza A, Di Trapani D, Laudicina VA, Morici C, Ødegaard H (2016b) Nitrous oxide emissions in a membrane bioreactor treating saline wastewater contaminated by hydrocarbons. Bioresour Technol 219:289-297

Mannina G, Cosenza A, Di Trapani D, Capodici M, Viviani G (2016c) Membrane bioreactors for treatment of saline wastewater contaminated by hydrocarbons (diesel fuel): an experimental pilot plant case study. Chem Eng J 291:269-278

Mannina G, Capodici M, Cosenza A, Di Trapani D, Laudicina VA, Ødegaard H (2017a) Nitrous oxide from moving bed based integrated fixed film activated sludge membrane bioreactors. J Environ Manage 187:96-102

Mannina G, Capodici M, Cosenza A, Di Trapani D, van Loosdrecht MCM (2017b) Nitrous oxide emission in a University of Cape Town membrane bioreactor: the effect of carbon to nitrogen ratio. J Cleaner Prod 149:180-190

Tsuneda S, Mikami M, Kimochi Y (2005) Effect of salinity on nitrous oxide emission in the biological nitrogen removal process for industrial wastewater. J Hazard Mater 119:93-98 